\title{
PIPA INFORMATIVA: JORNALISMO COMUNITÁRIO COMO UMA VIA DE ENFRENTAMENTO À PANDEMIA DA COVID-19
}

\author{
Melina de la Barrera Ayres \\ Universidade Federal de Santa Catarina \\ melina.ayres@gmail.com \\ Juliana Freire Bezerra \\ Universidade Federal de Santa Catarina \\ freire.bezerra.bez@gmail.com
}

\begin{abstract}
Resumo
Esta comunicação relata a experiência do projeto de extensão Jornalismo e Ação Comunitária (JAC), criado no Curso de Jornalismo da UFSC, durante a pandemia da Covid-19. O projeto visa aproximar os estudantes às realidades populares e empoderar as comunidades a partir da comunicação comunitária. Assim, os discentes são incitados a realizar projetos de comunicação não só voltados para as comunidades, mas construídos com elas. Diante da pandemia, apresentou-se o desafio: Como colocar o projeto em andamento respeitando as orientações de distanciamento social? O grupo criou, remotamente, junto às comunidades do Maciço do Morro da Cruz, em Florianópolis, a série jornalística Pipa Informativa. O intuito desta produção impressa e digital é preencher lacunas de informação de pertinência popular na pandemia. Para tanto, tem o apoio do Instituto Padre Vilson Groh, do Conselho Comunitário do Monte Serrat e da Associação de Professores da UFSC. Entre abril e agosto de 2020, período descrito neste trabalho, os materiais produzidos alcançaram mais de 5.000 famílias via redes sociais (Facebook e Instagram), WhatsApp e panfletos impressos.

Palavras-chave: Jornalismo Comunitário. Enfrentamento da Covid-19. Maciço do Morro da Cruz.
\end{abstract}

\section{PIPA INFORMATIVA: COMMUNITY JOURNALISM AS A WAY TO FACE THE COVID-19 PANDEMIC}

\section{Abstract}

This communication reports the experience of the extension project Jornalismo e Ação Comunitária (JAC), created in the Journalism Course at UFSC, during the Covid-19 pandemic. The project has the purpose to bring students closer to popular realities and empower communities based on community communication. Thus, students are encouraged to carry out communication projects aimed at the communities and co-created with them. Facing the pandemic, the challenge arose: How to get the project underway while respecting the guidelines for social distance? The group remotely created, with the communities of the Maciço do Morro da Cruz, in Florianópolis, the journalistic series Pipa Informativa. The purpose of this print and digital production is to fill information gaps of popular relevance in the pandemic. Therefore, it has the support of the Padre Vilson Groh Institute, the Monte Serrat Community Council and the UFSC Teachers Association. Between April and August 2020, the period described in this paper, the materials produced reached more than 5.000 families via networks (Facebook and Instagram), WhatsApp and printed flyers.

Keywords: Communitary Journalism. Facing Covid-19. Maciço do Morro da Cruz.

\section{PIPA INFORMATIVA: PERIODISMO COMUNITÁRIO COMO VIA PARA ENFRENTAR LA PANDEMIA DE COVID-19}

\section{Resumen}

Esta comunicación relata la experiencia del proyecto de extensión Jornalismo e Ação Comunitária (JAC), creado en el Curso de Periodismo de UFSC, durante la pandemia de Covid-19. El proyecto busca aproximar a los estudiantes de las realidades populares, y empoderar a las comunidades a partir de la comunicación comunitaria. De este modo, los discentes son estimulados a realizar proyectos de comunicación no solo relativos a las comunidades sino, sobre todo, construidos con ellas. Frente a la pandemia se presentó el desafío: ¿Cómo poner en marcha el proyecto respetando las orientaciones de distanciamiento social? El grupo creó, remotamente, en conjunto con las comunidades del Maciço do Morro da Cruz, en Florianópolis, la serie periodística Pipa Informativa. El objetivo de esta producción impresa y digital es llenar los vacíos de información de pertinencia popular durante la pandemia. Con este objetivo, cuenta con el apoyo del Instituto Padre Vilson Groth, del Consejo Comunitario de Monte Serrat y de la Asociación de Profesores de UFSC. Entre abril y agosto de 2020, periodo descrito en este trabajo, los materiales producidos alcanzaron a más de 5.000 familias vía redes sociales (Facebook e Instagram), WhatsApp y panfletos impresos.

Palabras clave: Periodismo Comunitario. Enfrentamiento al Covid-19. Maciço do Morro da Cruz. 


\section{INTRODUÇÃO}

A pandemia global da Covid-19 afeta a todos, mas não da mesma maneira. Estudos comprovam que a intensa desigualdade social que acarreta a pobreza em alguns países tem contribuído para que o índice de letalidade da doença seja maior entre as pessoas que vivem em realidades populares (MAGALHÃES; CARDOSO, 2020; FIOCRUZ, 2020; TEIXEIRA et al., 2020).

No Brasil, práticas básicas de prevenção contra a doença sequer são possíveis em muitos desses contextos (FIOCRUZ, 2020). A falta de acesso à água e saneamento básico, condições precárias de moradia, renda familiar insuficiente para o sustento diário são alguns dos fatores que dificultam as populações empobrecidas de redobrar os cuidados com a higiene e praticar o isolamento social ${ }^{1}$. Além disso, a proliferação de conteúdos falsos nas mídias sociais, a diferença entre classes sociais no que toca o acesso a direitos e a instabilidade política do contexto brasileiro agravam a crise sanitária, econômica e de saúde.

Cobrar, portanto, do poder público a criação, o fortalecimento e a efetividade de políticas sociais direcionadas à proteção da vida em contextos vulneráveis tem sido tarefa de diversas iniciativas de jornalismo comunitário em todo o país. Além disso, estas iniciativas cumprem o papel de abastecer as populações das comunidades com informação confiável e pertinente ao universo popular.

É em meio a este movimento comunicacional que professores e estudantes do Departamento de Jornalismo da Universidade Federal de Santa Catarina (UFSC) criaram o projeto de extensão Jornalismo e Ação Comunitária (JAC). A iniciativa vincula-se à disciplina Jornalismo Comunitário, ministrada na graduação pela professora Melina de la Barrera Ayres (que coordena o projeto), e ao grupo de pesquisa Jornalismo e Conhecimento do Programa de Pós-Graduação em Jornalismo (PPGJOR), por meio da pesquisa da doutoranda Juliana Freire Bezerra, sob orientação do professor Eduardo Meditsch ${ }^{2}$. O projeto conta igualmente com a participação dos estudantes de Jornalismo Klaymara Silva ( 6 fase), que trabalha na equipe de Redação da Pipa Informativa; Diogo

\footnotetext{
${ }^{1}$ Sobre isso ver a reportagem jornalística Desigualdade eleva letalidade da Covi-19 em favelas: https://www.dw.com/pt$\underline{\mathrm{br} / \text { desigualdade-eleva-letalidade-da-covid-na-favela-diz-estudo/a-53586352. }}$

${ }^{2}$ Nesta pesquisa de doutorado, busca-se construir, por meio da pesquisa-ação, a aproximação entre estudantes de Jornalismo e realidades populares para a construção de iniciativas de jornalismo comunitário feitos pela e para as comunidades do Maciço do Morro da Cruz. A movimentação inicial destes pesquisadores, articulando lideranças comunitárias e graduação em Jornalismo da UFSC contribuiu para a criação do JAC, seu objeto empírico de pesquisa. Vale salientar que a existência do JAC é fruto do trabalho e da integração coletiva entre comunidades, graduação e pósgraduação em Jornalismo da UFSC, fortalecendo o tripé que ancora a universidade pública: o ensino, a pesquisa e a extensão.
} 
Medeiros ( $6^{\mathrm{a}}$ fase), que realiza a diagramação e as ilustrações do material; e Daniela Muller ( $7^{\mathrm{a}}$ fase), que também se dedica à produção de ilustrações dos materiais informativos ${ }^{3}$.

O intuito do JAC é aproximar a universidade pública das realidades populares, com vistas ao empoderamento comunicacional das comunidades e ao aperfeiçoamento da formação cidadã em Jornalismo, conforme orientam as atuais Diretrizes Curriculares Nacionais (DCNs) para as Graduações de Jornalismo. Este documento indica que o egresso em Jornalismo, além de saber "interagir com pessoas e grupos sociais de formações e culturas diversas e diferentes níveis de escolaridade" (2013, p. 3) , precisa desenvolver a competência pragmática de "elaborar, coordenar e executar projetos de assessoria jornalística a instituições legalmente constituídas de qualquer natureza, assim como projetos de jornalismo em comunicação comunitária, estratégica ou corporativa" (MINISTÉRIO DA EDUCAÇÃO, 2013, p. 4, grifo nosso). Desta forma, no JAC os estudantes são incitados a colaborar com projetos de comunicação não só voltados para as comunidades, mas construídos com elas. O aporte teórico-metodológico que inspira o projeto ancora-se nos princípios democráticos, participativos, dialógicos e horizontais da Comunicação Popular e da perspectiva extensionista presente na obra de Paulo Freire ${ }^{4}$

Em razão desta perspectiva, o JAC utiliza a práxis e o diálogo como caminho orientador de execução dos seus projetos. O primeiro método consiste em compreender a realidade concreta das camadas populares como ponto de partida e de retorno da reflexão coletiva, a fim de gerar ações de comunicação pertinentes e transformadoras nas comunidades. Por sua parte, o diálogo permite que a práxis se efetive em termos de reflexão e prática coletivas. É por meio do diálogo, da troca entre saberes populares e científicos, que as ações do JAC visam propiciar a produção coletiva de conhecimentos críticos sobre o mundo, bem como estimular o protagonismo popular nas ações de comunicação e jornalismo comunitários.

Diante da pandemia da Covid-19, contudo, o seguinte desafio foi apresentado ao grupo: Como colocar o projeto em andamento respeitando as orientações de distanciamento social? Isto é, como construir ações de comunicação e jornalismo com as comunidades sem estar nelas presencialmente e sem conhecê-las previamente? A seguir relatamos os caminhos que o JAC encontrou na primeira etapa do projeto (desenvolvida de abril a agosto de 2020) para produzir

\footnotetext{
${ }^{3}$ As fases do curso de Jornalismo em que os graduandos se encontram referem-se ao período analisado neste trabalho, abril a agosto de 2020 .

${ }^{4}$ A orientação teórico-metodológica do JAC é marcada fundamentalmente pela concepção de extensão formulada pelo pedagogo brasileiro Paulo Freire. Na obra Extensão ou Comunicação? ([1968], 2010), o autor argumenta que, em uma perspectiva educativa transformadora do mundo, não caberia aos extensionistas transferirem os saberes científicos para as camadas populares, mas construírem junto com elas conhecimentos que lhes possibilitem ser protagonistas do processo de mudança das injustiças sociais que acometem suas realidades. Neste processo educativo, o acadêmico disposto ao diálogo, igualmente aprende com o sujeito popular. Desta forma, ambos os atores sociais têm a chance de, mediatizados pela realidade social, avançarem juntamente na superação de uma compreensão ingênua sobre o mundo para uma crítica.
} 
Pipa Informativa: jornalismo comunitário como uma via de enfrentamento à pandemia da Covid-19

remotamente panfletos impressos e digitais pertinentes às realidades comunitárias no cenário da pandemia. Chamados de Pipa Informativa, o intuito dos materiais é preencher lacunas de informação relacionadas à pandemia nas comunidades do Maciço do Morro da Cruz, em Florianópolis-SC.

\section{RECRIANDO AÇÕES DE JORNALISMO COMUNITÁRIO EM TEMPOS DE PANDEMIA}

O JAC nasce de demandas populares concretas e se reinventa para atendê-las desde o início de sua criação em abril de 2020. O fator que impulsionou o projeto de extensão em plena pandemia da Covid-19 foi a carta pública Um presente para um futuro, assinada pelo padre Vilson Groh ${ }^{5}$. No documento, escrito em meados de março, e disponibilizado em formato digital, o padre indicava que o combate à Covid-19 em contextos empobrecidos precisaria incluir diversas ações, entre elas, as informativas. "Principalmente de informação oficial, das autoridades de saúde. Com objetividade, clareza, linguagem e o uso da tecnologia. Com proposições que considerem as particularidades e limitações desses locais, para uma efetiva proteção das pessoas [...]” (INSTITUTO PE. VILSON GROH, 2020, s.p).

Partindo dessa demanda concreta, desse chamamento, o grupo começou a se organizar de forma remota. Um dos primeiros passos foi o contato com o Instituto Padre Vilson Groh, que tem atuação reconhecida na Grande Florianópolis, com frentes de ação em diversas comunidades da região. Desta conversa, estabeleceu-se como área de atuação do JAC o Maciço do Morro da Cruz. Um complexo de 17 comunidades localizado na região central de Florianópolis, onde residem cerca de 22.500 pessoas, as quais compõem aproximadamente 5.600 famílias, segundo dados estimados pela Prefeitura Municipal de Florianópolis $(2008)^{6}$. Algumas dessas comunidades, como a do Monte Serrat, estão situadas nas proximidades da Universidade Federal de Santa Catarina e foi justamente com ela que o JAC estabeleceu sua primeira ligação, por meio do contato com o então presidente do Conselho Comunitário local, Patrício da Cruz.

\footnotetext{
${ }^{5} \mathrm{O}$ padre Vilson Groh é uma liderança de referência em Florianópolis, por ser um elo da articulação entre diversos atores sociais e as comunidades locais. Em 1978, escolheu migrar para as periferias da cidade e fez do Maciço do Morro da Cruz seu lugar de morada. Ali, há mais de 30 anos trabalha com vistas a colaborar com o fortalecimento da cidadania e da educação para a transformação social. Desde 2010, tem ampliado com mais potência o seu raio de atuação com a criação do Instituto Pe. Vilson Groh, que atende a região metropolitana de Florianópolis por meio de uma rede de colaboradores formada por assistentes sociais, psicólogas, educadores e diversas organizações da sociedade civil, entre elas, a UFSC.

${ }^{6}$ Embora este dado tenha mais de dez anos, esta é a informação mais recente ofertada pela Prefeitura Municipal de Florianópolis, durante o planejamento de obras do PAC, em 2008. O Maciço do Morro da Cruz é constituído por 17 comunidades, a saber: Mariquinha, Monte Serrat, Tico Tico, Morro do 25, Morro do Horácio, Morro da Penitenciária, Morro da Queimada e Jagatá, Morro do Céu, Rua Ângela Laporta, Rua José Boiteux, Rua Laudelina da Cruz, Vila Santa Vitória, Vila Santa Clara, Serrinha, Alto da Caeira e Mocotó (PREFEITURA MUNICIPAL DE FLORIANÓPOLIS, 2008).
} 


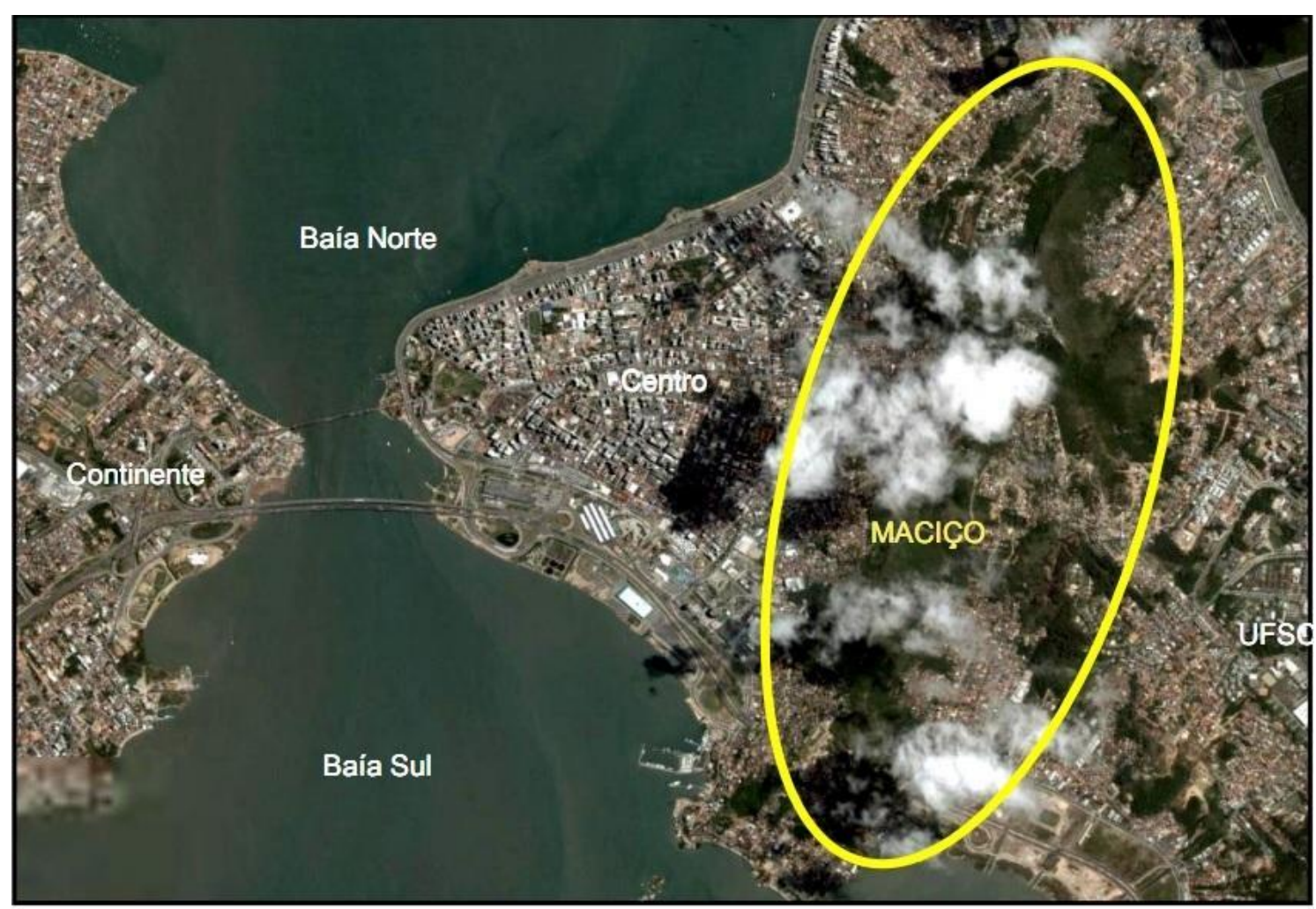

Figura 1: Mapa Florianópolis - Comunidade Monte Serrat.

Fonte: Prefeitura Municipal de Florianópolis, 2008.

Desde abril de 2020, a equipe do JAC realiza esta articulação de forma remota, por meio de reuniões mensais na plataforma Zoom, mensagens de texto via Whats App e ligações ao telefone. A periodicidade dessas duas últimas formas de contato varia, dependendo das demandas encontradas nas etapas de produção e distribuição da Pipa Informativa. O desafio do JAC tem sido estabelecer esta relação com organizações sociais e lideranças comunitárias destas localidades, sem conhecê-las previamente e sem poder estar presencialmente nas comunidades. Da parceria firmada com o Instituto Padre Vilson Groh (IVG) e o Conselho Comunitário do Monte Serrat resultou a Pipa Informativa, uma série jornalística disponibilizada em formato de panfleto impresso e digital.

O material tem como público-alvo os moradores e moradoras do complexo de comunidades do Maciço do Morro da Cruz. Diversos estudos (TOMÁS, 2012; REBOLLAR, SCHUCH, LOCH, 2013) demonstram que essa população é composta em grande medida por pessoas de baixa renda, muitas moradoras de habitações em situação de precariedade, no que toca, por exemplo, o abastecimento de água ${ }^{7}$. Ainda que isso seja uma constante, é preciso ressaltar

\footnotetext{
${ }^{7}$ Em Florianópolis, a ocupação do Maciço do Morro da Cruz "remonta do início do século XX. Inicialmente a área foi ocupada por escravos recém libertos e, em seguida, pela população pobre que foi expulsa da área central da cidade em nome de um movimento sanitarista para a renovação urbana. Na década de 1940, porções da floresta ombrófila densa ali existente estavam desmatadas sob o argumento de minimizar as consequências trazidas pela malária, o que facilitou as primeiras ocupações da área [...]. Atualmente o Maciço Central do Morro da Cruz é
} 
também a heterogeneidade de situações de vida. Elas refletem a própria complexidade e diversidade das comunidades brasileiras. Em entrevistas com algumas lideranças comunitárias locais, detectamos que no Maciço do Morro da Cruz há pessoas com diferentes hábitos de leitura, graus de escolaridade, acesso à internet, fontes de renda etc. A opção do JAC pela produção de materiais impressos resultou da busca por atender esses diferentes perfis, levando em conta aquelas pessoas que sofrem com as desigualdades digitais, pessoas recém-alfabetizadas, idosos e crianças, segundo as informações ofertadas em abril de 2020 pelo então presidente do Conselho Comunitário do Monte Serrat, Patrício da Cruz. A opção pelos materiais digitais, por sua vez, que são disparados sobretudo via WhatsApp, visa ampliar o raio de alcance das reportagens. Entre abril e agosto de 2020, seis materiais jornalísticos foram produzidos sobre saúde e acesso a direitos no cenário de pandemia da Covid-19. A Associação de Professores da UFSC (Apufsc) tem apoiado o projeto de extensão, com a impressão de alguns desses materiais em tiragens diferenciadas que atingem entre duas mil a cinco mil famílias ${ }^{8}$.

Como a produção é desenvolvida integralmente de forma remota em respeito às orientações de distanciamento social reforçadas pela UFSC; o IVG e o Conselho Comunitário do Monte Serrat auxiliam a equipe do JAC compartilhando o material nas suas redes virtuais (Facebook, Instagram e Whats $A p p$ ) e distribuindo presencialmente nas comunidades. Além disso, ambas as organizações promovem a aproximação entre o JAC e outras lideranças comunitárias do Maciço do Morro da Cruz. Atualmente, cerca de vinte lideranças comunitárias deste complexo de comunidades colaboram com a distribuição da Pipa Informativa via Whats App, objetivando assegurar o acesso à informação de interesse público popular para mais pessoas.

\section{Práxis como método das ações de comunicação do JAC}

Em virtude da impossibilidade de estar in loco, e com o objetivo de produzir materiais jornalísticos de interesse público popular, o JAC conta com uma rede de parceiros para selecionar também quais assuntos serão tratados em cada panfleto e sob qual abordagem. Isso porque, conforme orienta a pedagogia freiriana, é do universo cultural popular que devem surgir os temasgeradores a serem trabalhados de forma crítica, reflexiva e coletiva pelos atores do processo educativo. Transpondo esta premissa para a comunicação comunitária, entende-se que a ação

ocupado essencialmente por população de baixa renda, em locais que, de acordo com o Código Florestal Brasileiro, consiste em Áreas de Preservação Permanente - APP” (REBOLLAR, SHUCH, LOCH, 2013, p. 4).

${ }^{8} \mathrm{O}$ primeiro panfleto impresso do JAC teve uma tiragem de cinco mil exemplares com o intuito de atender todas as famílias do Maciço do Morro da Cruz e as pessoas que não têm acesso à internet ou o costume de usá-la, como os idosos, por exemplo. No entanto, para garantir que mais edições da Pipa Informativa fossem disponibilizadas neste formato, a equipe do JAC diminuiu o número de tiragens (de cinco mil para duas mil) e o tamanho do panfleto (de A4 para A5). Com o corte de custos, a equipe conseguiu o apoio da Apufsc para a impressão de mais três edições do panfleto e tem complementado a distribuição dos materiais via redes sociais e aplicativo de mensagens. 
Pipa Informativa: jornalismo comunitário como uma via de enfrentamento à pandemia da Covid-19

comunicativa somente ganha pertinência social quando está inserida na realidade popular e parte dela. Paulo Freire coloca que, neste processo de troca entre saberes populares e científicos, a reflexão sobre a própria prática precisa ser constante e realizada de forma dialógica para que todos os participantes, por meio dos diversos pontos de vista, avancem na superação do saber ingênuo para um saber crítico sobre o mundo, impulsionador da ação consciente sobre ele (FREIRE, [1997], 2004).

Esta metodologia da práxis dialógica freiriana ancora o JAC tanto em sua convivência interna (entre os integrantes do projeto de extensão), quanto externa (nas conversas com as lideranças comunitárias e os parceiros do projeto). Nestas comunicações externas, além da seleção dos temas geradores a serem trabalhados em cada panfleto (as pautas jornalísticas), são feitas avaliações sobre o material já produzido. Antes de ser divulgada, a aprovação de cada Pipa Informativa é realizada conjuntamente com as lideranças comunitárias, que recebem os panfletos via Whats $A p p$ antes de serem impressos, para a realização de possíveis ajustes.

No que se refere às reuniões internas, estas são realizadas duas vezes por semana por videoconferência na plataforma Zoom para discutir o processo de produção dos panfletos, tanto no âmbito imagético, como no textual. A despeito de cada integrante do JAC ter uma função, seja de orientação, revisão, apuração e redação, ilustração e diagramação, a frequência destas reuniões internas é importante porque a produção de cada panfleto é fruto de um empenho coletivo e colaborativo, no qual todos participam ativamente ${ }^{9}$. Dessa forma, por mais que existam pessoas responsáveis por apurar as reportagens, por exemplo, frequentemente o grupo inteiro interfere sobre a forma de apresentação das informações e, se necessário, complementa a etapa de checagem. O objetivo é gerar materiais escritos em linguagem clara e próxima do universo vocabular do leitor, mas, ao mesmo tempo, densa em contextualização e conteúdo crítico. A esta premissa soma-se o desafio de cumprir estes objetivos em panfletos impressos de tamanho reduzido (formato A5), tornando ainda mais complexo o processo de escolha das informações inseridas nos materiais, da combinação entre imagem e texto e sua linguagem. Esta ação demanda um engajamento coletivo para a elaboração de soluções. Além das reuniões internas no Zoom, o uso de plataformas de trabalho colaborativo como o Google Drive e as possibilidades de trocas de mensagens no Whats App facilitam esse processo. Destas reflexões e ações coletivas, a equipe chegou à conclusão que abordar um tema por vez em cada panfleto impresso é a melhor saída para contextualizar o assunto - tendo em vista a perspectiva crítica que o JAC assume - e torná-lo mais claro e objetivo - tendo em vista a sua preocupação didática.

\footnotetext{
9 (Autor 1- Profa. Coordenadora, Autor 2- Jornalista Responsável, Eduardo Meditsch- Prof. Orientador, Klaymara Silva - Redação, Daniela Muller- Ilustração e Diogo Medeiros - Ilustração e Diagramação.
} 
Pipa Informativa: jornalismo comunitário como uma via de enfrentamento à pandemia da Covid-19

Além disso, o grupo tem investido em materiais para redes sociais na Internet (Facebook e Instagram) e aplicativo de mensagem (Whats $A p p$ ), buscando não só reforçar o conteúdo e atingir um público maior, mas complementar, em materiais extras, assuntos pertinentes ao universo popular que não puderam ser tratados no material impresso em virtude de limitação espacial. Acrescido a isso, algumas reuniões internas da equipe são dedicadas exclusivamente a discutir a obra de Paulo Freire. Estas reuniões impulsionam a autoavaliação da equipe no que toca sua coerência discursiva e prática, bem como a reinvenção da metodologia freiriana para a práxis dialógica da comunicação e do jornalismo comunitários no cenário de pandemia da Covid-19.

\section{EM BUSCA DE AÇÕES DE COMUNICAÇÃO TRANSFORMADORAS}

Desde a produção do primeiro panfleto impresso, em abril de 2020, a equipe do projeto de extensão foi guiada pelas lideranças comunitárias na busca por conscientizar as comunidades sobre a gravidade da Covid-19 e as formas de prevenção ${ }^{10}$. Naquele momento, despontavam os primeiros casos da doença nas comunidades e a maioria dos moradores só conhecia a pandemia "por ouvir dizer". Desta forma, as mensagens da série foram produzidas buscando alertá-los sobre a situação que se agravaria em breve, caso não se protegessem ${ }^{11}$. Seguindo a mesma perspectiva praxiológica, panfletos digitais sobre o auxílio emergencial do Governo Federal foram produzidos. Um indicando o calendário de pagamento; outro, o caminho que as pessoas poderiam percorrer, caso tivessem o benefício negado, tendo direito a ele.

A despeito da colaboração mútua e do diálogo remoto com as lideranças comunitárias que trabalham ou moram nas comunidades, a equipe enfrentou impasses no que toca a questão da pertinência dos conteúdos produzido. Um caso emblemático foi o panfleto impresso produzido sobre o Centro de Referência de Assistência Social (Cras), que é ligado à prefeitura. Atendendo à demanda dos parceiros comunitários, o JAC elaborou um material didático sobre os serviços prestados pelo órgão. Isso porque, segundo as lideranças comunitárias, apesar de ser a porta de

\footnotetext{
${ }^{10}$ Esse primeiro material foi chamado de Xô, Corona. O nome foi escolhido com o intuito de utilizar uma linguagem local, próxima do universo vocabular dos moradores de Florianópolis, e transmitir a mensagem que medidas de prevenção contra a doença precisavam ser realizadas para a pandemia ser controlada. No entanto, em virtude de casos ocorridos a nível mundial de hostilização contra pessoas que contraíram a Covid-19, a equipe optou por trocar o nome da série jornalística. Ela foi nomeada então de Pipa Informativa, em alusão a um traço cultural das comunidades do Maciço do Morro da Cruz: o uso lúdico da pipa.

${ }^{11}$ No material, uma carta do padre Vilson Groh foi incluída ao final, com o intuito de reforçar as orientações de prevenção. Conforme apontam estudos de Paul Lazarsfeld, Bernard Berelson e Hazel Gaudet na década de 1940, as mensagens advindas de "fora" das comunidades, como as midiáticas, têm mais chances de serem apropriadas nas comunidades, quando endossadas por lideranças de referência local.
} 
Pipa Informativa: jornalismo comunitário como uma via de enfrentamento à pandemia da Covid-19

entrada para o atendimento público aos cidadãos em situações de vulnerabilidade social, o Cras é desconhecido por grande parte dos moradores das comunidades.

Contudo, só após o material ter sido impresso, a equipe do JAC soube em carta pública feita pelo IVG que a população estava tendo dificuldades para acessar os serviços de assistência social no atual contexto ${ }^{12}$. Esta situação demonstra, ao mesmo tempo, como a apuração jornalística pode ser limitada pela impossibilidade de estar presencialmente no local de investigação e, por conseguinte, a dependência do JAC em relação aos olhares dos profissionais e moradores das comunidades para a produção de conteúdos de pertinência popular, sobretudo neste momento. Com o intuito então de complementar o primeiro panfleto e denunciar a situação de dificuldade de acesso ao Cras, foram produzidas duas edições virtuais do Pipa Informativa, disseminadas pela rede de parceiros em mídias sociais (Facebook e Instagram) e aplicativo de mensagens de celular (Whats App). Ambas foram feitas no modelo de problema-solução. O intuito foi orientar como os cidadãos, diante da dificuldade de acesso ao Cras (problema), devem proceder para exigir o acesso a este direito social (solução).

Durante a apuração do primeiro material, verificou-se que a ineficiência do Cras decorre da quantidade insuficiente de funcionários disponibilizados pelo governo para atender o aumento das demandas dos cidadãos na pandemia. Como orientação para a solução deste problema, foi indicado que os cidadãos poderiam se organizar coletivamente junto ao Conselho Comunitário, para denunciar com mais força política a situação no Ministério Público e na ouvidoria da Prefeitura. Na segunda Pipa virtual sobre o assunto, o JAC colaborou para a criação de um movimento popular nas redes sociais, visando cobrar do poder público o fortalecimento do Cras e a contratação de mais funcionários para atender a população. As hashtags \#fortaleceoCRASSC, \#fortaleceoCRASFloripa, \#aceleraMPSC foram lançadas nas redes sociais e disseminadas em redes virtuais das lideranças comunitárias e da equipe do JAC em julho. Os resultados desta ação ficaram visíveis em agosto, quando a Defensoria Pública de Santa Catarina contactou a equipe de assistência social do IVG perguntando sobre esta mobilização. Além disso, o material produzido pelo JAC serviu para endossar os argumentos do IVG em resposta sobre o assunto encaminhada ao Ministério Público.

De todo este processo, o JAC tirou algumas lições. A mais importante relaciona-se à importância da reflexão coletiva para o aprimoramento da prática (práxis: ação-reflexão-ação). Foram nas reuniões internas destinadas a discutir a obra de Paulo Freire, que o JAC avançou na autocrítica para o melhoramento de seu trabalho. Surgiram nestas reuniões inclusive ideias para

12 Sobre isso ver o texto “Nossas vidas importam!" escrito pelo IVG em julho de 2020: https://www.redeivg.org.br/noticias/nossas-vidas-importam/. Acesso em julho 2020. 
Pipa Informativa: jornalismo comunitário como uma via de enfrentamento à pandemia da Covid-19

reinventar o método dialógico e praxiológico freiriano ao atual contexto em que a comunicação entre universidade e comunidades só pode ser realizada de forma remota. Da discussão coletiva decorreu o entendimento de que o JAC precisava estabelecer uma maior aproximação com os moradores e as lideranças das comunidades na produção de seus conteúdos, vide o impasse que enfrentou na produção do material sobre o Cras. Um grupo virtual de comunicação organizado pelo IVG com várias lideranças do Maciço do Morro da Cruz foi criado para atender esta necessidade. E as consultas individuais para a aprovação de cada material, antes deste ser impresso, passaram a contemplar mais lideranças comunitárias.

Além disso, contatos com as lideranças comunitárias foram implementados como práticas recorrentes. Outro ensinamento advindo das reflexões coletivas da equipe relaciona-se ao papel social que o JAC possui. Por meio destes panfletos, tornou-se evidente para o grupo que o posicionamento ético do JAC com a produção da Pipa Informativa, além de abastecer a populações com informações pertinentes ao seu contexto, consiste em denunciar a violação de direitos, bem como estimular a discussão sobre inclusão social e a responsabilidade cidadã.

Seguindo esta perspectiva, o terceiro material impresso da Pipa Informativa foi produzido em julho de 2020 com o objetivo de conscientizar o seu público-alvo, principalmente a juventude, acerca da necessidade de seguir praticando o distanciamento social e evitando aglomerações. A pertinência deste conteúdo surge em um momento em que a curva de casos da Covid-19 está em ascensão no estado de Santa Catarina, ao passo que as pessoas flexibilizam medidas de prevenção contra a doença. Para colaborar com as orientações de autocuidado na pandemia e integrar ainda mais o projeto à perspectiva comunitária, talentos artísticos de contextos empobrecidos estão sendo incitados pelo JAC a produzir músicas sobre o assunto. Válido reforçar que estas ações são desenvolvidas integralmente de forma remota.

\section{A busca pela coerência entre ética e estética}

Ao rigor crítico e jornalístico empenhado na série Pipa Informativa para a produção de reportagens de perspectiva cidadã e emancipadora, é somado o esforço estético. Na obra Pedagogia da Autonomia, Paulo Freire afirma: "A necessária promoção da ingenuidade à criticidade não pode ou não deve ser feita à distância de uma rigorosa formação ética ao lado sempre da estética. Decência e boniteza de mãos dadas" (2004, p. 36). Com este norte teórico-metodológico como horizonte, o JAC visa também fomentar a autoestima comunitária por meio de seus materiais. Com o objetivo de desconstruir os estereótipos de violência, miséria e tristeza com que frequentemente as comunidades são representadas no jornalismo corporativo, o grupo investe em uma construção imagética positiva e alegre das localidades e seus moradores. O intuito não é ocultar os problemas 
existentes nas comunidades, mas visibilizar socialmente a complexidade cultural, econômica e cidadã que entretece os contextos comunitários.

Dada a impossibilidade de estar presencialmente nas localidades, o Google Earth e os perfis de lideranças e associações comunitárias em redes sociais na Internet, como Facebook e Instagram, têm sido recursos encontrados pela equipe do JAC para conseguir representar visualmente as comunidades e seu moradores de forma verossímil, bem como em sua diversidade e beleza. A coerência estética é igualmente buscada na linguagem verbal adotada nos panfletos. Visando a aproximação com o universo vocabular dos leitores, a Pipa Informativa tem apostado em um tom oral em todas as suas publicações, ao ponto de alguns materiais terem sido desenvolvidos em formato de diálogo e histórias em quadrinhos (Figuras 2 e 3). Chamar a atenção dos leitores já nas primeiras linhas do panfleto e usar as opções de palavras do universo vocabular da comunidade são preocupações constantes.

As escolhas do nome e da logomarca da série informativa igualmente demonstram a preocupação do JAC em representar a identidade popular. A pipa colorida, além de ser um traço cultural e lúdico das comunidades do Maciço do Morro da Cruz, representa, igualmente, um olhar para o alto, como se ampliasse o espectro do universo dos sonhos a serem almejados nestas comunidades, como comentou Lucieni Braun, gerente executiva do IVG, em uma das reuniões virtuais realizadas com o JAC. Já o uso do quebra-cabeça geométrico chinês Tangram (Figura 4), utilizado para compor a logomarca, simboliza a ideia de que a força comunitária está na criatividade e ação coletiva, onde ninguém é deixado para trás e todos são valorizados em sua diversidade humana. Na segunda etapa deste projeto, a ideia é contribuir com oficinas jornalísticas para que moradores e lideranças comunitárias construam seus próprios jornais comunitários, sendo eles os protagonistas da sua história. 


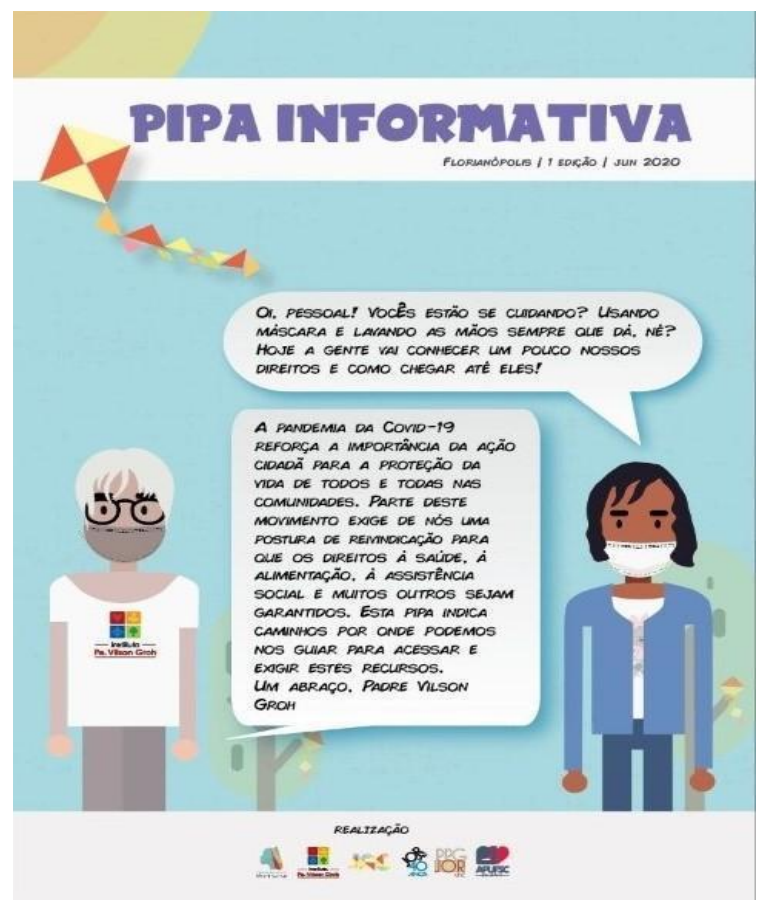

Figura 2: Capa do material impresso sobre o Cras Fonte: Arquivo JAC, 2020.

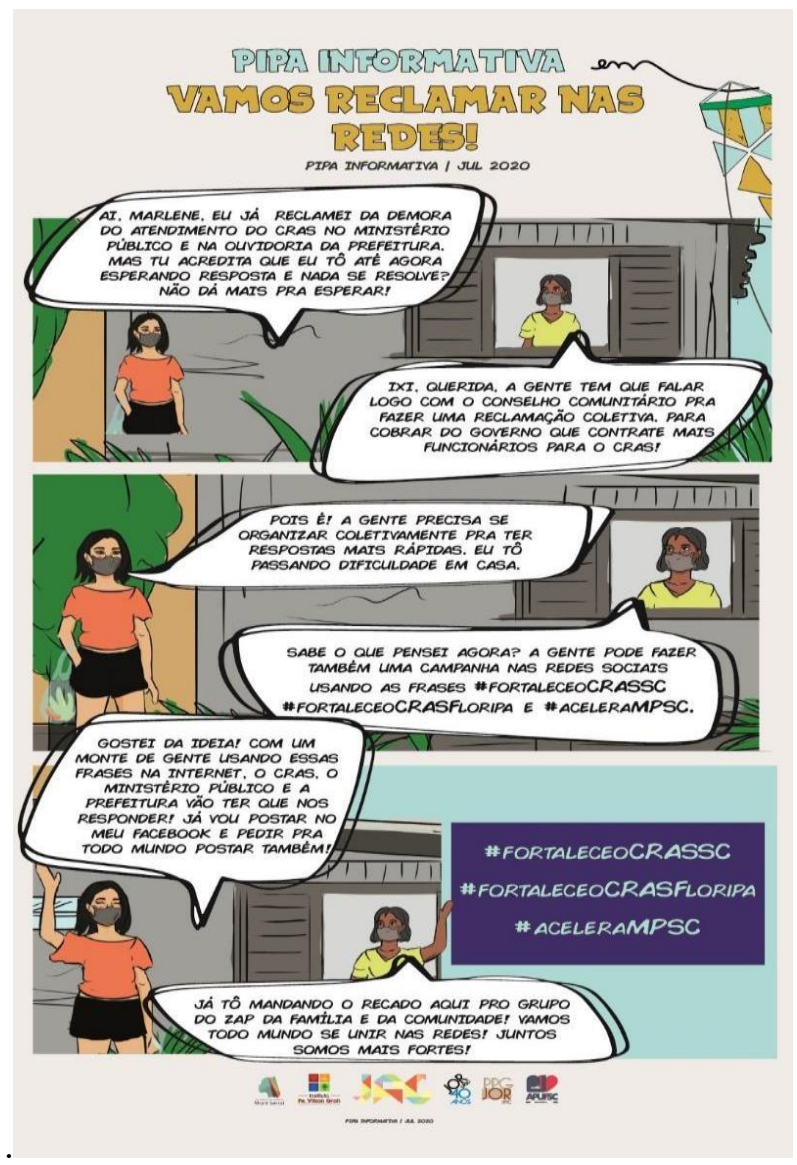

Figura 3: Material digital sobre ineficiência do Cras Fonte: Arquivo JAC, 2020. 


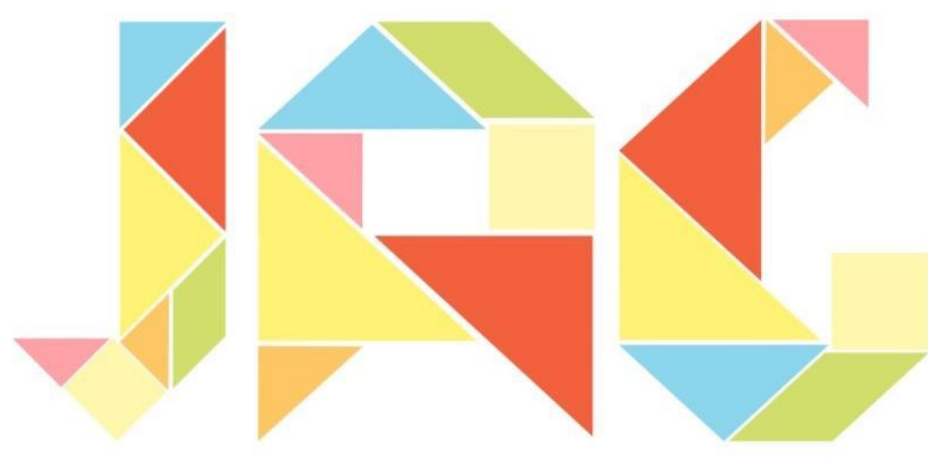

\section{Jornalismo Ação Gomunitária}

Figura 4: Logomarca do JAC em Tangram

Fonte: Arquivo JAC, 2020.

\section{CONSIDERAÇÕES FINAIS}

O projeto de extensão Jornalismo e Ação Comunitária do Departamento de Jornalismo da UFSC foi criado em um momento que a princípio parecia pouco oportuno. Era início de pandemia da Covid-19 no Brasil, as aulas na Instituição estavam suspensas e nenhum dos integrantes do JAC conhecia sequer as comunidades populares com que trabalharia. No entanto, foi justamente o contexto de crise que impulsionou o engajamento da equipe. $\mathrm{Na}$ busca por contribuir com uma das frentes de combate à pandemia nos contextos empobrecidos de Florianópolis, a equipe se movimentou para preencher lacunas de informação de pertinência pública popular. Deste esforço nasceu não só o JAC, mas o produto que marca sua primeira fase de existência: a série jornalística Pipa Informativa. Ela é desenvolvida de forma integralmente remota pela equipe, em respeito às orientações de distanciamento social reforçadas pela UFSC. Vale destacar igualmente que o projeto não conta com nenhum tipo de apoio. Os alunos da graduação que se envolveram disponibilizam seu conhecimento e seu tempo voluntariamente. Os materiais são impressos graças ao aporte da APUFSC que se comprometeu com a impressão de quatro edições.

Assim, colocar o projeto em prática no atual cenário foi desafiador. Mas, para cada obstáculo que previamente parecia difícil de ser superado, uma solução inventiva foi criada por meio da reflexão e da ação coletiva do grupo e dos parceiros. O pensamento teórico-metodológico de Paulo Freire configura-se como crucial para o delineamento destas ações. Por meio dele, o grupo buscou maneiras de dialogar com as comunidades, usando as possibilidades que detinha. Isto é, reinventando o método freiriano para a situação concreta vivenciada no contexto histórico em vigor. O estabelecimento de relações de confiança, mesmo que construídas de forma remota, com 
Pipa Informativa: jornalismo comunitário como uma via de enfrentamento à pandemia da Covid-19

as lideranças comunitárias do Maciço do Morro da Cruz é fruto do comprometimento dos atores sociais envolvidos no projeto com as realidades populares e da consciência da potencialidade transformadora das ações de comunicação e jornalismo que desenvolvem juntos com elas.

Em menos de cinco meses (abril a agosto) e respeitando as orientações de distanciamento social, o JAC consolidou-se como projeto de extensão institucionalizado junto à UFSC, firmou parcerias e apoios para impressão e distribuição dos materiais que produz e tem levado a cerca de cinco mil famílias informações de pertinência popular relacionadas à pandemia da Covid-19. Além disso, tem sido motivado a iniciar os projetos de jornalismo comunitário no Maciço do Morro da Cruz, uma demanda já evidenciada por moradores e lideranças locais. Reforçando o tripé entre ensino, pesquisa e extensão contribui desta forma com uma formação cidadã em Jornalismo, para os estudantes que participam do projeto, e com o fortalecimento do protagonismo e da cidadania comunitários nas ações de comunicação.

\section{REFERÊNCIAS}

FIOCRUZ. Boletim Socioepidemiológico da Covid-19 nas favelas: análise da frequência, incidência, mortalidade e letalidade por Covid-19 am favelas cariocas, n. 1, 2020. Disponível em: https://portal.fiocruz.br/sites/portal.fiocruz.br/files/documentos/boletim_socioepidemiologico s_covid_nas_favelas_1.pdf Acesso em 29 de julho de 2020.

FREIRE, P. ([1968], 2010). Extensão ou Comunicação? 14 ed. Rio de Janeiro: Paz e Terra, 2010. FREIRE, P. ((1997], 2004). Pedagogia da Autonomia: saberes necessários à prática educativa. São Paulo: Paz e Terra, 2004.

INSTITUTO PE. VILSON GROH. Um presente para um futuro. Disponível em: https://www.redeivg.org.br/noticias/um-presente-para-um-futuro/. Acesso em 30 de julho de 2020.

LAZARSFELD, P., Berelson, B., GAUdeT, H. The People's Choice. New York: Duell, Sloan \& Pierce, 1944.

MAGALHÃES, G.; CARDOSO, L. Editorial: Efeitos econômicos e distributivos da pandemia de coronavírus no Brasil. Revista de Economia e Agronegócio- REA, v. 18, n. 1, 2020, p. 1-12. MINISTÉRIO DA EDUCAÇÃO. Resolução no 1, de 27 de setembro de 2013. Disponível em:http:/ portal.mec.gov.br/index.php?option $=$ com_docman\&view $=$ download\&alias $=14242$ rces001-13\&category_slug=setembro-2013-pdf\&Itemid=30192. Acesso em 12 de maio de 2020.

PREFEITURA MUNICIPAL DE FLORIANÓPOLIS. Projetos e ações no Maciço do Morro da Cruz, 2008. Disponível em: http://www.pmf.sc.gov.br/arquivos/arquivos/pdf/07_12_2009_17.54.05.21d784d2f1c7f637453 6382850dda3da.pdf. Acessado em 10 de agosto de 2020, às $10 \mathrm{~h}$. 
Pipa Informativa: jornalismo comunitário como uma via de enfrentamento à pandemia da Covid-19

REBOLLAR, N.; SCHUCH, A. LOCH, C. Diagnóstico das condições de saneamento na comunidade do Maciço do Morro da Cuz- Florianópolis- SC- Brasil. Revista Extensão em Foco, $\mathrm{n}^{\circ}$ 8, p. 1-14 2013. Disponível em: https://revistas.ufpr.br/extensao/article/view/35311/21873. Acesso em 30 de julho de 2021, às 11 h30.

TEIXEIRA, K.; CARVALHO, K.; MEDEIROS, A.; BARBOSA, I. Indicadores de casos e óbitos por Covid-19 e sua relação com fatores contextuais: um estudo ecológico na cidade de Natal-RN. Brazilian Journal of Development. Curitiba, v. 6, n.6, p. 40689-40703, jun. 2020.

TOMÁS, E. D. Antigos e novos olhares sobre o Maciço do Morro da Cruz [tese]: de não território a território do Pac-Florianópolis. Programa de Pós-Graduação em Geografia da Universidade Federal de Santa Catarina, Florianópolis, SC, 361 p., 2012.

Recebido em: 20/08/2020

Aceito em: 13/08/2021 